\title{
Contenedores que vomitan recogedores
}

Roc Albalat 


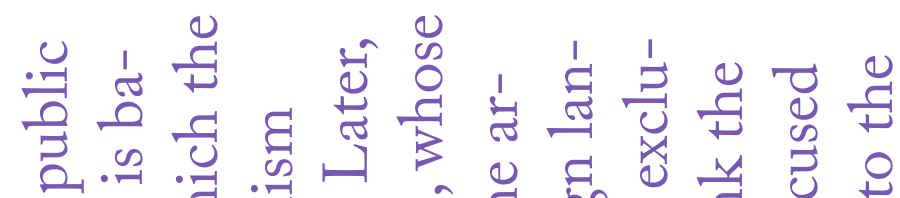

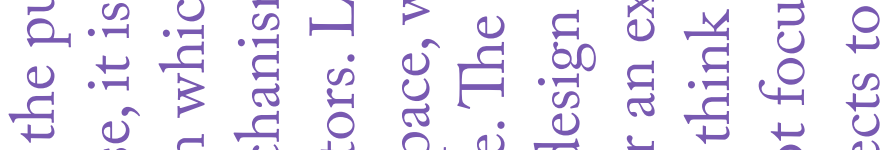

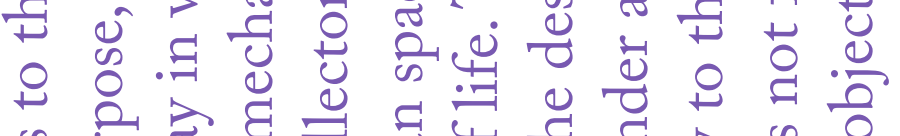

क

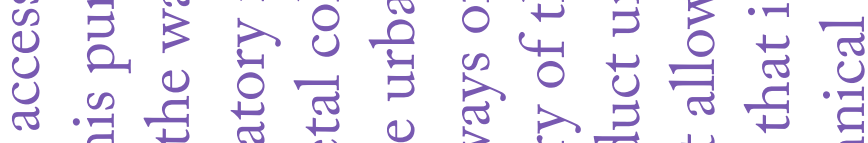
on:

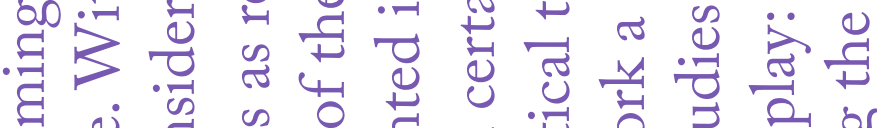

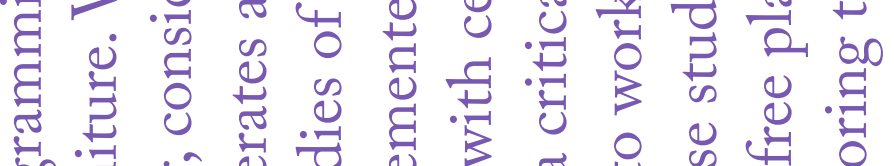

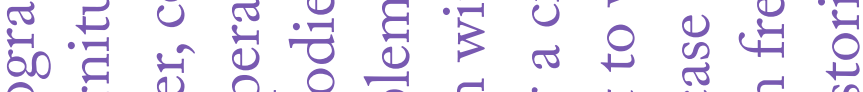

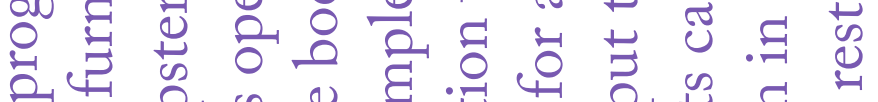
论 者

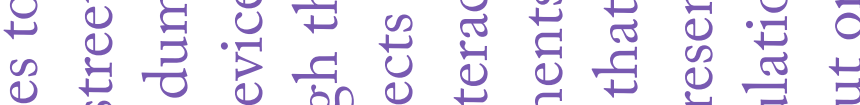

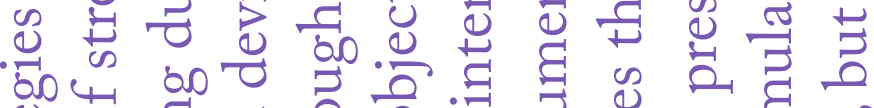
क्षे

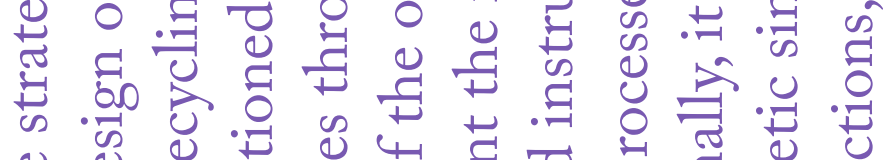

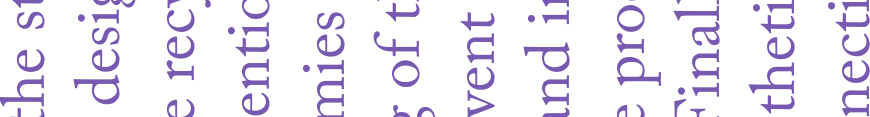

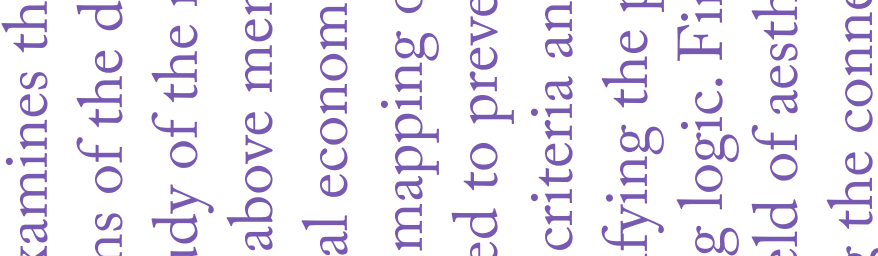
है U 는

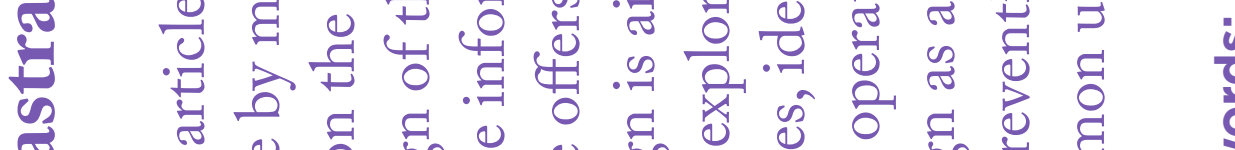

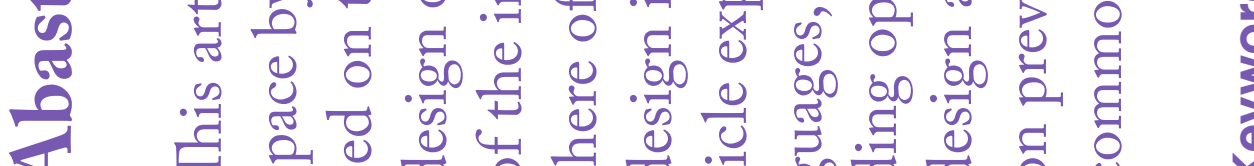

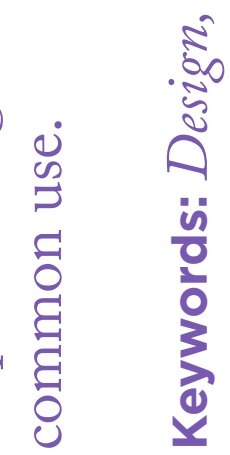




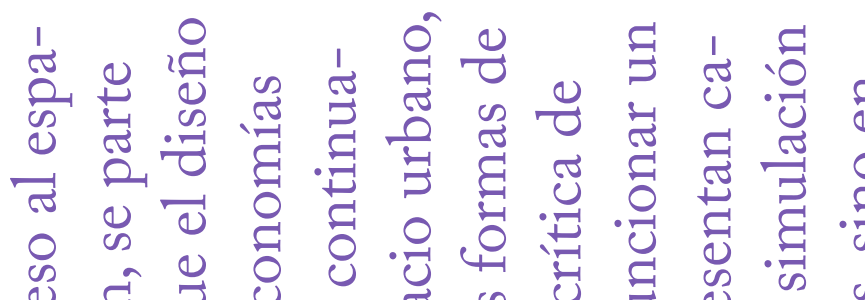

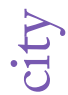

U ש

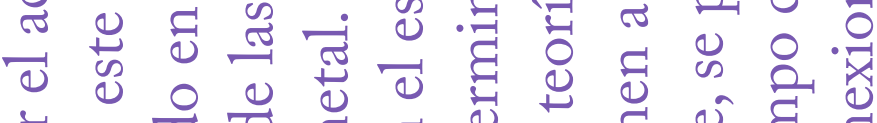

芯

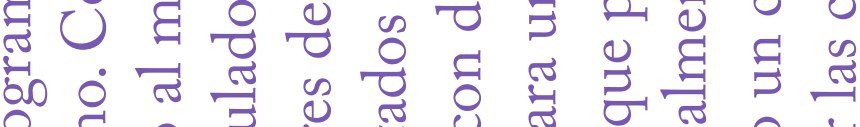

율



$\infty$ כ

胥

:

.

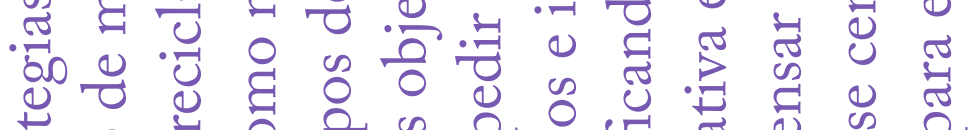
䒕 0 出 苟

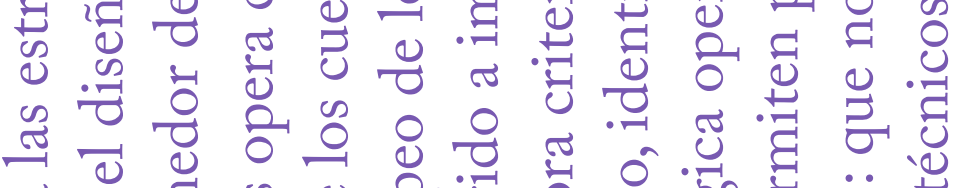

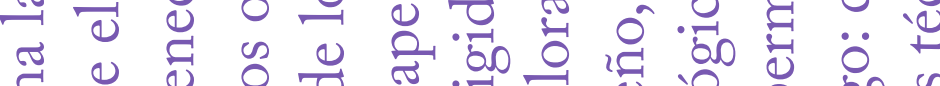
.

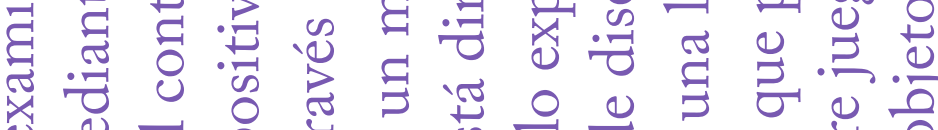

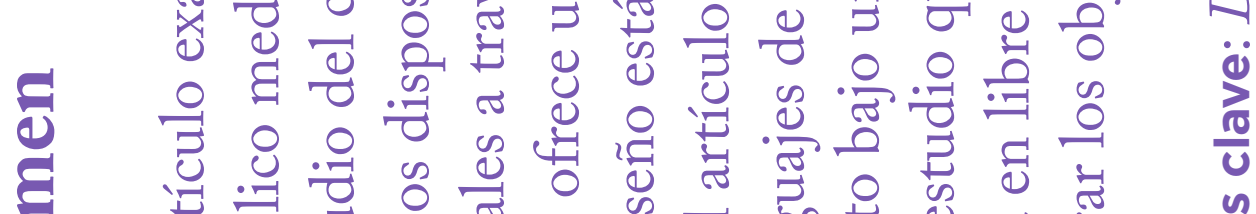
岂.

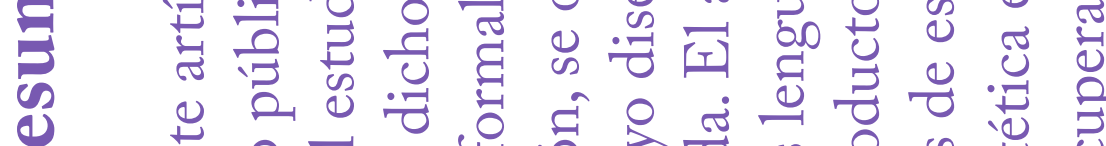

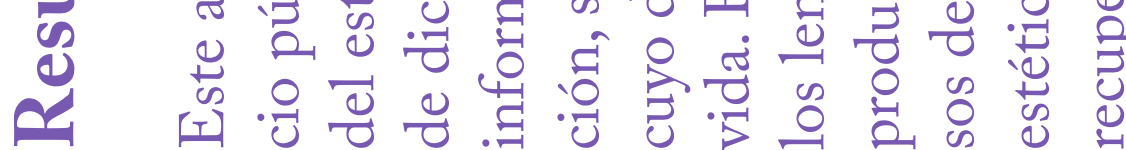




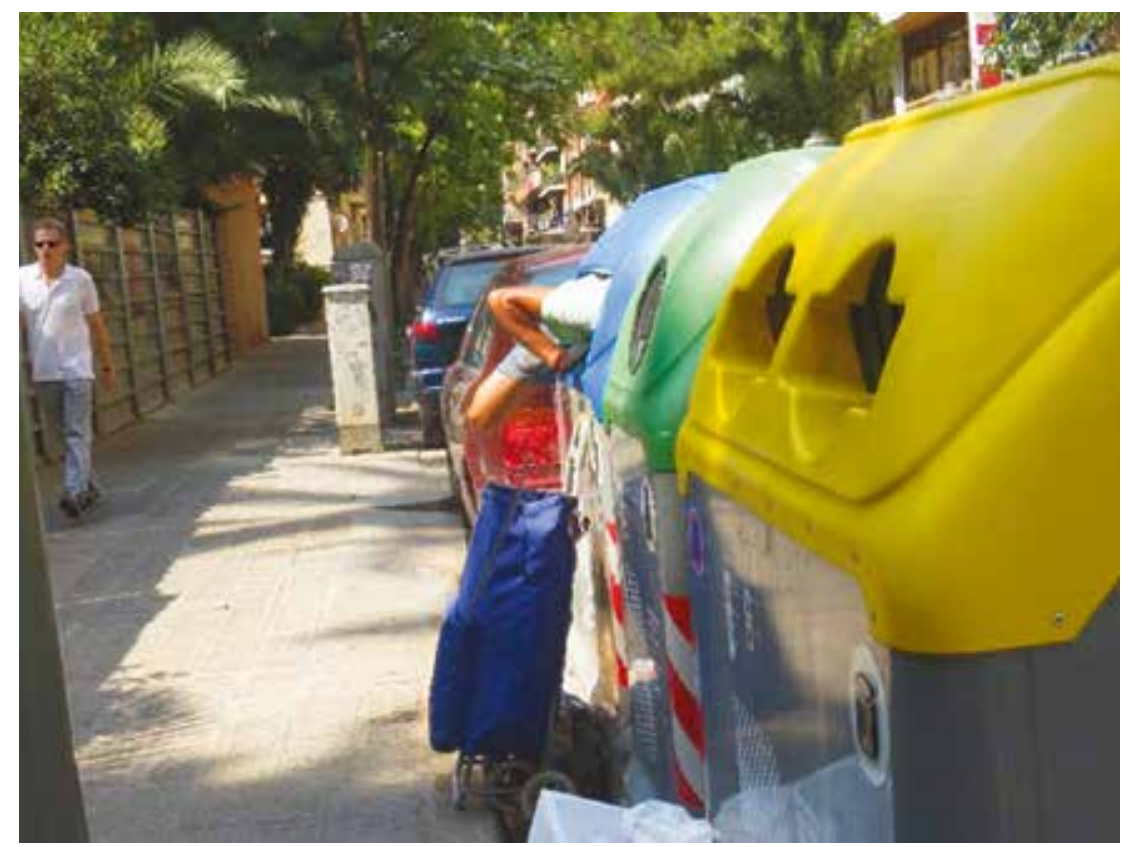

En la fotografía vemos a un esforzado recogedor salir de un contenedor. Entendemos la imagen en este sentido porque partimos de una mirada que tiende a poner el acento en la acción humana. Sin embargo, la fotografía está publicada por José Antonio Millán en una web que lleva el título Lo que vomitan los contenedores (Millán, 2014). El sentido figurado nos indica que es como si el contenedor vomitara al sujeto. ¿Pero es realmente un sentido "figurado"? ¿¡o se da realmente la acción del objeto, que induce al recogedor a ser vomitado? El término vomitar, procede de la raíz latina vomitāre, el significado del cual era arrojar, lanzar o conducir hacia afuera algo. Esta acepción también se aplicaba al tránsito por los pasillos, entradas y salidas (vomitorium) por los que se accedía a los anfiteatros y circos en la Antigua Roma. Hoy en día seguimos empleando la palabra vomitorio para referirnos a los accesos a los estadios, diseñados para conducir grandes aglomeraciones de personas. Por tanto, cabe pensar en cierto tipo de agencia que permite que los equipamientos arrojen, lancen o conduzcan personas, mediante un diseño que facilite tal vómito.

El autor de la fotografía del contenedor la ha publicado bajo el epígrafe El recogedor de metal como Jonás, comparando al recogedor con el profeta bíblico que fue vomitado por un gran pez, después de tres días y tres noches en su interior. En el relato del Antiguo Testamento, Jesús asimila 
tal milagro al de su propia resurrección (Biblica, 1999). La resurrección del recogedor, vomitado por el mobiliario urbano es una imagen sugerente que nos permite renovadas lecturas, tiene la ventaja de ofrecernos una visión más nítida de las acciones de un dispositivo. Nos permite distinguir las normativas que franquean cuerpos y aparatos, así como la problematización de sus efectos políticos, estéticos y sensoriales. Si entendemos el objeto (contenedor) como inscripto en un juego de poder, su diseño se revela bajo una función normativa (vetar al recogedor). Con este propósito, el diseño del contenedor integra un vomitorio. Se trata de una emergente función estratégica, requerida por los lobbies de empresas que rentabilizan la recogida de residuos urbanos. Veamos un ejemplo:

\section{"Se han convocado dos concursos abiertos a empresas y universidades de diseño cuyo fin es el diseño de dispositivos que impidan o dificulten el hurto de material en los contenedores" (Ecoembes, 2014).}

El veto a otros beneficiarios de la actividad de recogida está implícita en las instrucciones del diseño. La forma del contenedor, su estructura, se diseña delimitando las capacidades de afectación ante los cuerpos con los que ha de interactuar. Si se consigue un buen diseño, en los términos establecidos por el concurso, el contenedor vomitará más recogedores. El sociólogo Michael Callon afirma que "los objetos técnicos pueden, más o menos explícitamente, definir y distribuir los roles para los seres humanos y no humanos" (Callon, 1991, p. 137). En el proyecto de contenedor, los roles se distribuyen de la forma siguiente: se ha de facilitar el ingreso de cuerpos no humanos, así como impedir el paso a cuerpos humanos.

\section{Ingreso de cuerpos no humanos}

Marx comienza el libro uno de El capital afirmando que el modo de producción capitalista se presenta "como una inmensa acumulación de mercancías” (Marx, 2010, p. 43). En las aglomeraciones urbanas del capitalismo avanzado, tal acumulación genera cantidades inflacionistas de basura (un problema agravado por las estrategias comerciales orientadas a la obsolescencia programada). La emisión de contaminantes en vertederos e incineradoras se relaciona con un estado de excepción ecológica, que carga de responsabilidad a nuestra especie ante el resto del planeta (Braidotti, 2013, p. 83). No obstante, en virtud de la movilización que genera, el relato medioambiental tiende a ser fagocitado por una estrategia que propone afrontar el colapso desde el urbanismo y las 
políticas urbanas. Es el discurso de la ciudad inteligente y su construcción de marca. La smart city promueve un espacio urbano donde lo general llama a lo particular a adaptarse a ambientes ya programados, y lo hace mediante el despliegue de nuevos estándares:

Se trata de unos contenedores aún más inteligentes, pensados para garantizar la buena separación de los residuos. Disponen de un acceso controlado con una tarjeta magnética que registra a qué hora se ha abier to, el usuario o la cantidad vertida. Y envía estos datos a los centros de control. Así, los municipios pueden usar esta información para premiar o penalizar a los usuarios (Tort, 2013, p. 5c).

El diseño de las infraestructuras se basa en un sofisticado conductismo, que incorpora sistemas de compensación y exige la complicidad del usuario. La socióloga Patricia T. Clough define dichas técnicas como "mecanismos que (...) traducen la difusión de procedimientos burocráticos competitivos, de control y de mando político, en términos de protección de la vida de la población" (2008, p. 18). El lenguaje promocional de la ciudad inteligente apela al interés colectivo de no agravar la problemática ambiental (Albalat, 2016) y traduce dicho interés en términos de monitorización, premio y penalización. Sin embargo, me dispongo a argumentar cómo tales mecanismos están concebidos, no como un dispositivo ecológico, sino como una forma de explotar económicamente la actividad del usuario.

El reciclaje es una actividad esencial para los modos de producción y de consumo. Un proceso al que Deleuze y Guattari (1993) denominan phylum o linaje tecnológico: las estrategias dedicadas a la explotación de la potencia transformadora de la materia (la posibilidad de refundirla y de reutilizarla). Por ejemplo, mediante su reciclaje, el metal muda su condición de desecho y es transformado en un nuevo producto o en un engranaje. El contenedor es, en este sentido, el objeto que marca el umbral entre la materia sobrante de la maquinaria de consumo y el conjunto heterogéneo de fuerzas que explotará el devenir de su linaje (herramientas, combustible, puentes, armas, medios de comunicación). El usuario del contenedor tiene un papel clave en este proceso, realiza una actividad productiva (separación y almacenamiento de envases) de la que no es beneficiario. Esto se hace evidente si observamos el modelo europeo, que ha privatizado la rentable actividad de recogida y reciclaje de los desechos seleccionados por el ciudadano, mientras carga sobre los 
municipios el coste de gestión de residuos no clasificados ${ }^{1}$. Es decir, la persona usuaria paga con sus impuestos aquello que no puede ser reintroducido en el phylum. Por tanto, la primera función del contenedor de reciclaje (el ingreso de cuerpos no orgánicos) integra la acción ecológica a la fluidez de los procesos productivos.

\section{Expulsión de cuerpos humanos}

En cuanto al recogedor, ¿cuáles son los procesos que ponen en marcha su expulsión? El aumento del precio del metal y el cartón (junto con los efectos de la crisis económica y de las políticas migratorias) han provocado un aumento notable del número de personas que recuperan materiales de los contenedores de basura. Una parte de la población que no puede integrarse en los procesos productivos busca una salida mediante el recurso de los desechos. Se trata de una actividad en aumento, no integrada al circuito estándar del flujo del metal y que es considerada como un riesgo por el conglomerado empresarial que ostenta el mono-

${ }^{2}$ La recogida de residuos en España es un negocio controlado por un grupo de empresas multinacionales, todas ellas multadas por la Comisión Nacional de los Mercados y de la Competencia (CNMC) por "repartirse los clientes y las licitaciones públicas” (CNMC, 2015).

\footnotetext{
${ }^{3}$ El Ayuntamiento de Barcelona prohibe "escoger y seleccionar los residuos depositados en la vía pública, incluidos los que se encuentran dentro de los contenedores". (Ordenanza sobre el uso de las vías y los espacios públicos de Barcelona, modificada el 2010).
} polio del sector ${ }^{2}$. Sus capacidades de propiedad y dependencia ven como un riesgo la atracción del metal hacia los nuevos conjuntos económicos que acompañan a la presencia del recogedor. Ante ese riesgo, convocan un concurso que pone en marcha el proceso de proyección de un nuevo estándar: dispositivos que impidan o dificulten el hurto.

La expulsión de los cuerpos humanos del contenedor es una medida disciplinaria y de control, que viene a complementar otras medidas policiales. En el contexto de la ciudad-empresa, se establecen marcos estrechamente regulados y punitivos con ciertas formas de vida (la fotografía del contenedor está tomada en Barcelona, donde la ley prohíbe recoger basura de los contenedores ${ }^{3}$ ), pero la represión institucional no consigue impedir la recogida furtiva de residuos como modo de supervivencia. Para dicho fin, resulta más efectivo integrar las premisas a los lenguajes de diseño. Se trata de un agente más silencioso, oculto para aquellos grupos a los que no va dirigido. Al vincular la norma al ambiente urbano, la administración de las conductas se ha vuelto más inapelable, más sólida, más material. Y para materializarse, tiene que ser diseñada.

El imperativo de expulsar recogedores es "un gesto humano depositado, fijado, convertido en estereotipia y en poder de recomenzar" (Simondon, 1958, p. 155). El filósofo Gilbert Simondon advertía que la propia naturaleza del diseño de artefactos se inclina hacia la mitificación. La tecnología tiende a trasformar la historia en naturaleza, dado que dejamos de atender a mecanismos que fueron implementados tiempo atrás. El 
sociólogo Bruno Latour percibe tal efecto y lo condensa en la frase: "la tecnología es la sociedad hecha para que dure” (1991). Mediante la programación y el diseño de objetos e infraestructuras, incorporamos al ambiente futuros modelos de relación.

De este modo, el diseño se encarga de actualizar el sistema operativo de la ciudad, introduciendo nuevos estándares a las infraestructuras, como un refuerzo de la vía administrativa. Mediante la difusión de tales estrategias, se propicia el efecto de una estetización de los dispositivos normativos. La aceptación de los términos y condiciones de un diseño user friendly ha venido a substituir al burocratizado mundo moderno. En la novela El Castillo, Kafka da cuenta de la abominable presencia de la administración en la vida: "Nunca antes K. había visto en ninguna parte la administración y la vida hasta tal punto imbricadas, tan imbricadas estaban que a veces se tenía la sensación de que la administración y la vida habían tomado el lugar la una de la otra” (Kafka, 1998, p. 43). En un mundo donde la gestión de las conductas se vuelve más material, más sólida, parecería que un buen diseño ha tomado el lugar de la administración para confundirse con la vida.

Observemos de nuevo el prototipo de contenedor anti-recogedores: su diseño incorpora una mecánica de exclusión y la pone a funcionar ("en poder de recomenzar"). El nuevo estándar establece la polarización política del objeto. El lenguaje proyectivo integra conductas, elecciones y valores que quedan encerrados en la arquitectura del contenedor y apartados del debate público. Se trata de un diseño que oscurece la relación entre los impuestos ciudadanos, la administración de los bienes colectivos y la inversión en dispositivos de seguridad. Mediante la materialización de la lógica operativa, se disuelven la disensión y el conflicto en residuos innegociables y se produce un entorno incuestionable. Con este objetivo se convoca un concurso para diseñar el contenedor: el encargo a estudiantes y profesionales es el de relacionar los lenguajes técnico y político hasta volverlos inseparables. Y esta no es una cuestión trivial. Esta confusión inducida desde el campo del diseño es crucial para entender el actual ciclo económico capitalista, que se caracteriza, según el sociólogo francés Gilles Lipovetsky, por "la desregulación de las distinciones entre lo económico y lo estético" (Lipovetsky, Serroy, 2015, p. 10).

\section{Anti-objetos}

¿Es el contenedor el único agente de control infiltrado en el mobiliario urbano? El diseño anti-recogedores es un ejemplo actual, pero que se enmarca en la larga vocación del urbanismo moderno por canalizar el control de la conducta en las ciudades. La arquitectura y el diseño han servido durante mucho tiempo a los intereses de las élites urbanas para programar el acceso, el control y el uso del espacio por parte de diferentes grupos. El profesor Langdon Winner (1986, p. 23) nos brinda un caso paradigmático: el urbanista Robert Moses, renovador del trazado de Nueva York, proyectó puentes bajos en las carreteras para acceder a las playas de Long Island a la altura justa para que los autobuses no pudieran circular. De esta forma se aseguraba una forma inapelable de segregación, ya que el acceso estaba limitado al automóvil privado. Un artículo del historiador Daniele Porreta (2010) traza un conciso recorrido del urbanismo de control en Europa. Este texto expone cómo el miedo y la inseguridad han influido en la infraestructura de las 
ciudades y constata la formación de "una estética de la seguridad que guiaría la forma de las construcciones (...) El nuevo urbanismo estaría siempre más dominado por la fragmentación espacial y la segregación social" (Porretta, 2010). Esta estética de la seguridad ha impregnado el diseño moderno del mobiliario urbano. Se imponen medidas urbanísticas hostiles ante las conductas incívicas o no prescritas.

Un ejemplo común en Europa es el de los bancos con apoyabrazos (Figura 1). La posición del apoyabrazos impide que la gente esté tumbada. Con este diseño se quiere evitar que el banco lo utilice para dormir el grupo en aumento de los sin-techo. El cuerpo del sin-techo incomoda a las instituciones que gestionan los recursos turísticos en los centros históricos de las ciudades. En estos puntos conflictivos, donde conviven zonas de ocio turístico con diversidad de prácticas no prescritas, es donde las agencias de planificación urbanística tratan de dar respuestas operativas a la condición compleja y turbulenta de la ciudad. En Barcelona, por ejemplo, el aislamiento y protección del turista (ante las conductas imprevistas de otros sujetos) determina el diseño de las terrazas en La Rambla: delimitando su área con jardineras, de forma que queden diferenciados y que el cliente se sienta protegido. Otro ejemplo de esta estética de la seguridad son las "orejas de cerdo", el objeto que se muestra en la Figura 2: prótesis metálicas instaladas en las esquinas que suponen un obstáculo para las ruedas de los skaters. Se trata de un diseño originado en San Francisco y que se ha exportado a otras ciudades, con el objetivo de que estas prácticas no tengan lugar en puntos estratégicos del espacio urbano.

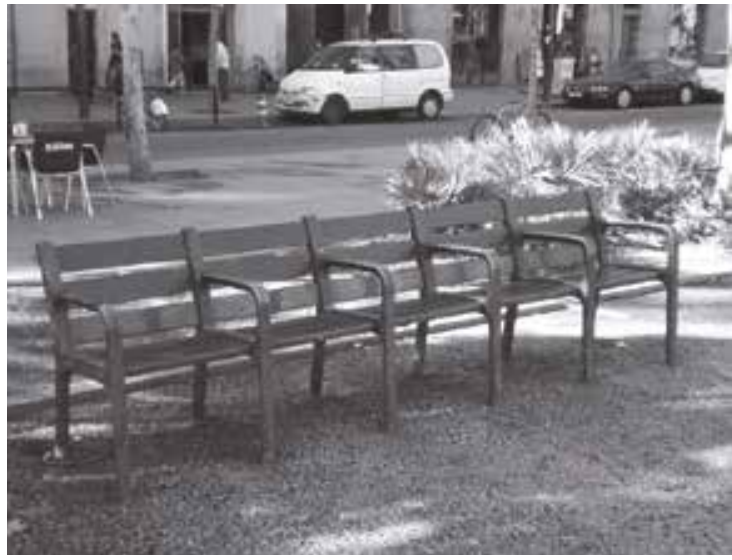

Fig. 1. Banco anti-indigente en la Rambla del Raval. Daniele Porretta. 2010.

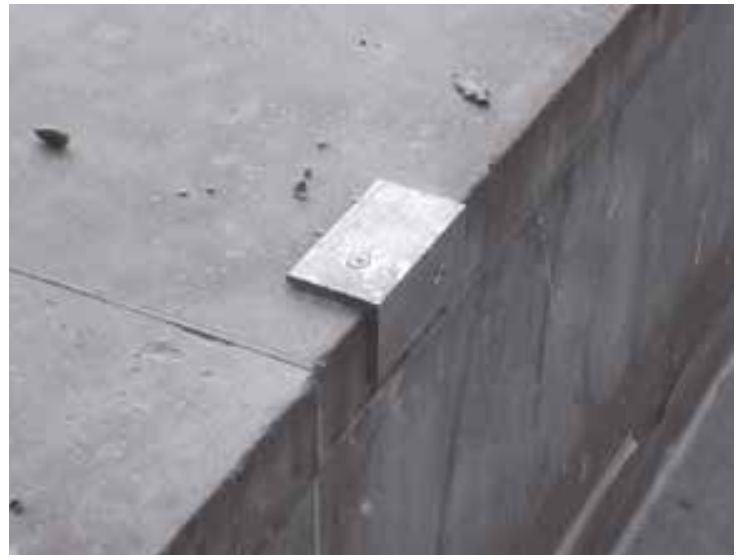

Fig. 2. Pig ear (oreja de cerdo) antiskater en la plaza de la Mercè. Daniele Porretta. 2010. 

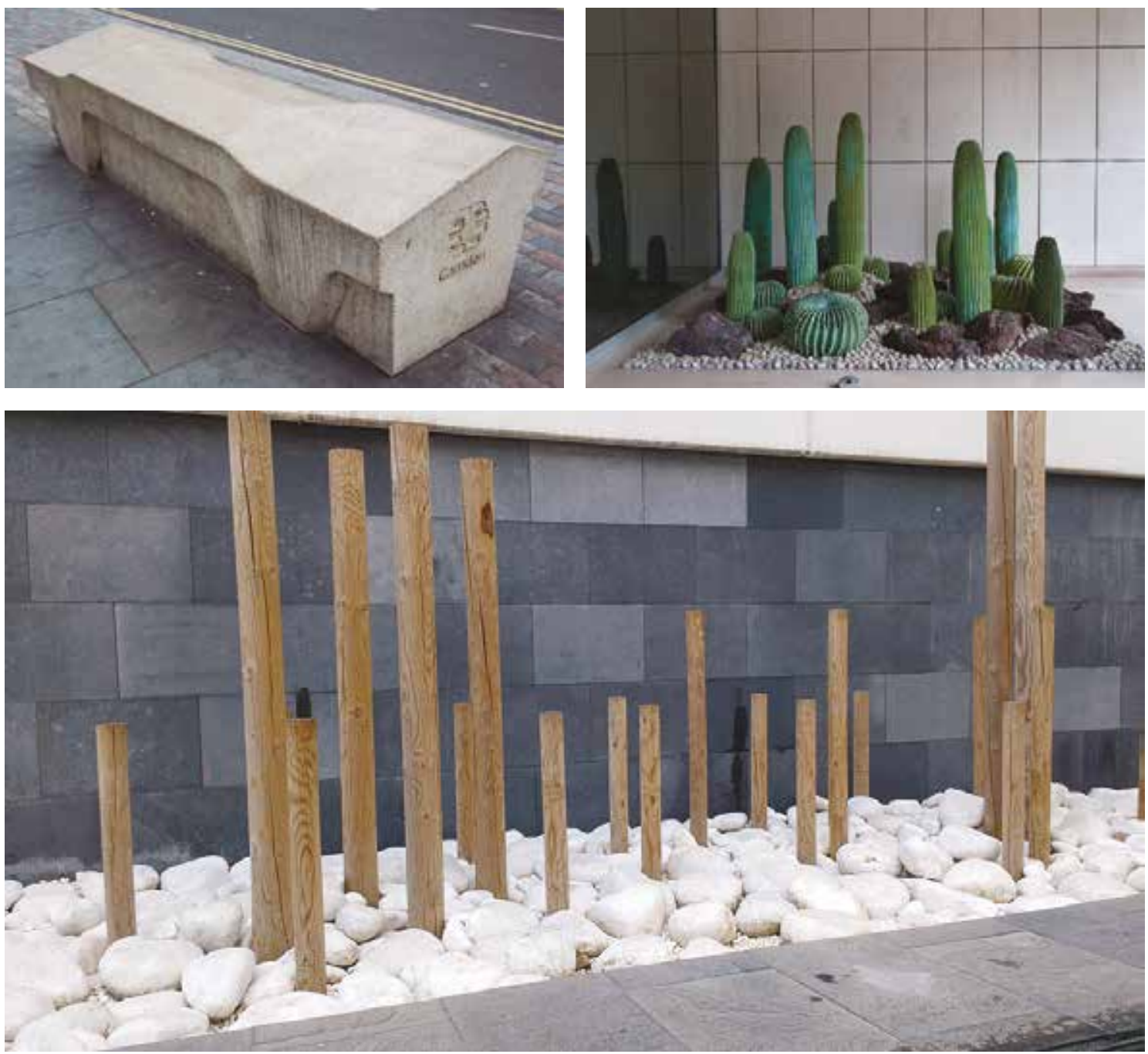

Fig. 3. Imagen de un Banco de Camden. The wub. Londres (Reino Unido).

Fig. 4. Anti Sites. Survival Group.

Fig. 5. Estética de seguridad. Roc Albalat. Castellbisbal. 2016.

El diseño del banco de Camden que muestra la Figura 3 también busca repeler al monopatín. Dificulta que la tabla se deslice por sus bordes, dotados de una forma fluctuante. Por otro lado, este diseño también impide encontrar una posición para dormir. Por tanto, el banco de Camden también repele a los sin-techo. La ausencia de hendiduras en las que esconder las drogas, ahuyenta también a los traficantes. Y para acabar, rechaza al grafitero, ya que tiene un recubrimiento especial para repeler la pintura. Un amplio abanico de medidas orientadas a determinar cuál es el uso normativo del banco. Su diseño es un auténtico Caballo de Troya contra las conductas no normalizadas. Descartado el banco, los amplios portales de bancos y oficinas podrían resultar una alternativa para el sin-techo, pero también en estas zonas urbanas se han instalado pinchos, ru- 
gosidades, esculturas, rampas o jardines hostiles como los que muestran la Figura 4 y la Figura 5. Todas ellas, medidas preventivas que convierten el espacio público en un espacio "anti-alguien". Los artistas franceses Survival Group iniciaron el año 2005 el proyecto fotográfico Anti Sites, anti lugares, que compila fotografías tomadas en lugares proyectados con un objetivo común: orientar, frustrar y disuadir a la gente de ciertas conductas. En su manifiesto, se muestran irónicos con tal afán normativo: "Pero ¿por qué ir a sentarse cuando hay tantos trabajo por hacer / bellos objetos confeccionados para ser comprados / películas, series y juegos para ver?" (Survival Group, 2005).

Gordan Savičić y Selena Savić (2013) son los coeditores del libro Unpleasant Design, un catálogo de diseños intencionadamente desagradables. Su investigación explora la relación entre el espacio, el diseño y la interacción social. Examinando cómo el espacio urbano es diseñado con efecto disuasorio para ciertos grupos y actitudes, los editores ponen de relieve el carácter inapelable del dispositivo físico. A diferencia de las interacciones con los guardias de seguridad o cuerpos policiales, las características físicas no son negociables. Su permanencia es definitiva y sin concesiones: es la imagen del consenso. El consenso debe entenderse aquí, no como un acuerdo armónico de intereses, sino en la acepción que le otorga Jaques Rancière: una apariencia que requiere hacer invisibles las disensiones. "En la que incluso los datos a partir de los cuales se deciden acuerdos y desacuerdos se consideran objetivos e incuestionables" (Rancière, 1998, p. 58).

\section{La solidificación de los lenguajes de diseño}

"Una vez que se produce el organismo individual, sin embargo, sus extensiones y cualidades ocultarán el proceso intensivo original y sus tendencias endógenas. En otras palabras, el proceso se convertirá en encerrado en el producto..."(DeLanda, 2009).

Tomando como esquema conceptual a Deleuze y su teoría de los ensamblajes, Manuel DeLanda adopta conceptos de la termodinámica (proceso intensivo) para definir las propiedades conectivas de los organismos. Una entidad individual (un cuerpo, un producto) tiene un conjunto indeterminado de capacidades para formar parte de otros ensamblajes. Los procesos intensivos corresponden a este conjunto abierto de potenciales interacciones. Aquello que permite que la relación entre el todo y las partes permanezca inacabado. 
En el texto citado, DeLanda expone cómo los productos se diseñan atendiendo a la producción de equilibrio en un sistema. Cada actualización cancela las capacidades del producto de ser un componente en otros ensamblajes. El diseño del objeto se centra en hacerlo incompatible con una amplia gama de potenciales ambientes morfológicos. Al abortar la conexión entre componentes, los lenguajes de diseño tienden a solidificarse. El diseño absorbe y sustenta la economía dominante, manteniendo las futuras interacciones en unos valores predictibles e impidiendo su libre juego: "instalar planetariamente un presente contra el libre juego de todo venir a la presencia. En pocas palabras: EL MUNDO SE ENDURECE”(Tiqqun, n.d.).

La compatibilidad del producto con otros cuerpos viene determinada por un cálculo estadístico de riesgo ante esos cuerpos. La práctica del diseño y del desarrollo técnico que queda sujeta a dicha lógica operativa, produce entidades que tienden a lo que hemos denominado una estética de la seguridad (banco de Camden, Figura 3). Son objetos que generan estratos sólidos y estables, imágenes que pierden su poder evocador, símbolos estancos sin poder de replicación especulativa. La solidificación de los lenguajes de diseño se manifiesta mediante el despliegue de estándares y se dirige a materializar la utopía de la ciudad inteligente.

\section{Diseño intensivo: carros mutantes}

“...pero este producto, a su vez, posee, además un conjunto bien definido de propiedades (extensivas y cualitativas) un conjunto abierto de capacidades para interactuar con otros individuos, orgánicos y no orgánicos" (DeLanda, 2009).

La imagen (página siguiente) muestra a otro recogedor de metal transportando sus bienes en un carro de supermercado al que ha adherido un compartimento trasero, adaptando un carro doméstico de la compra. Materiales reutilizados que se acoplan en una suerte de vehículo que permite al recogedor hacer su trabajo. Contrariamente al diseño de los contenedores, el diseño en estos carros parte de la recombinación de otros objetos. Forma parte de lo que el académico británico Matthew Fuller define como "una técnica para absorber la aparición inesperada, de otro modo irresoluble, de formas sociales; como una forma de arquitectura preventiva de zonas-deformación" (Fuller, 2016, p. 82). E1 recogedor de metal resuelve la distancia existente entre él y los modos de producción con una libertad de juego que no encontrábamos en el 


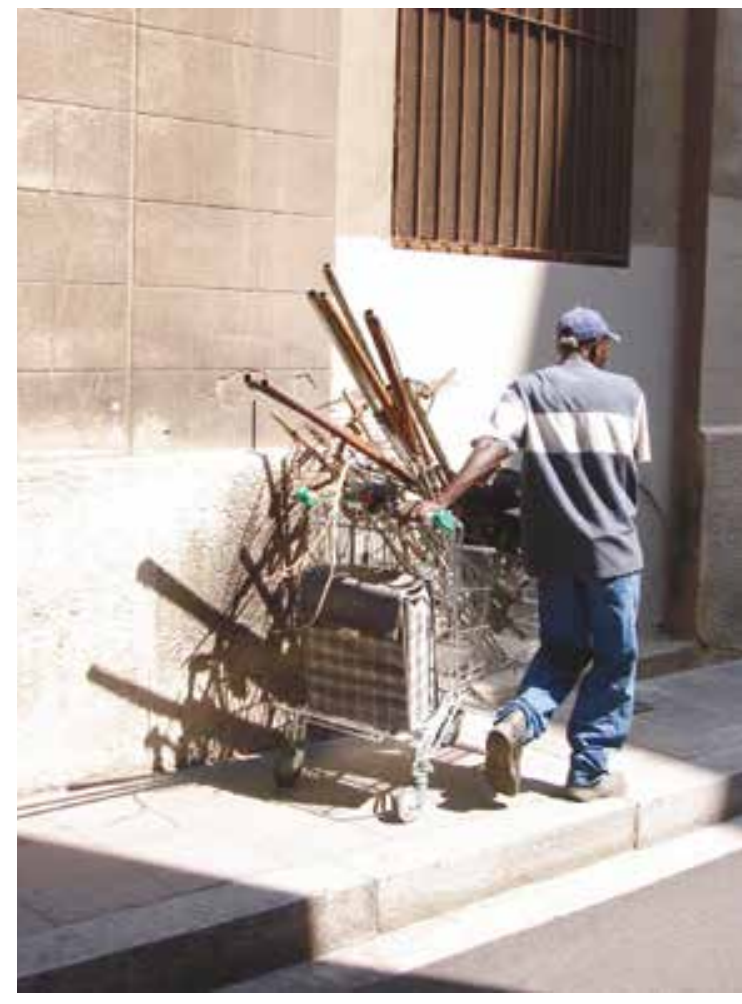

José Antonio Millán. Vehículos informales para la recuperación. Barcelona. 2011. diseño de los contenedores. Advirtiendo la determinación latente en el dispositivo económico, es capaz de desnaturalizar la performatividad de los productos, acoplar sus cuerpos y subvertir sus usos. E1 hecho que los productos originales no estén pensados para esos usos no detiene las capacidades de afectación y re-agenciamiento de los objetos.

El carro de la compra, símbolo de la sociedad de consumo (como tantas otras prótesis que ocupan el vacío ante la ausencia de los sujetos), queda atravesado por una paradójica función: reciclar los mismos envases que estaba programado a transportar en su función original. En este gesto, la agencia del objeto traza una línea de fuga. La presencia del recogedor propicia el cambio de polarización del carro de la compra, que presta su utilidad a otra forma de vida. Para el filósofo Giorgio Agamben "la constitución de una forma-de-vida coincide íntegramente con la destitución de las condiciones sociales y biológicas en las que ella se encuentra arrojada” (Agamben, 2014). La elevada dependencia del recogedor ante tales economías provoca que su subsistencia se base en el desgaste de los dispositivos.

El ejemplo de los carros mutantes nos permite pensar en una brecha en la determinación de los objetos, nos brinda la posibilidad de una agencia nómada. Es la muestra material de una distancia restituida a partir del ingenio y la recombinación. Sin embargo, es improbable que el carro diseñado por el recogedor entre en el catálogo de gadgets de la smart city. ¿Por qué motivo? No cumple la subsunción de prácticas normativas e interrumpe la complicidad ciudadana ante el orden previamente negociado. El objeto diseñado por el recogedor provoca un desplazamiento en las formas de habitar el espacio. Su práctica se asemeja a lo que el teórico 
cultural Michel de Certeau (2000) define como un uso táctico de los productos. Un uso que tiene como fin la oportunidad de escapar de las estrategias de producción.

El montaje y re-agenciamiento de los carros responde a una solución de diseño intensivo. La intensidad del lenguaje de diseño se entiende como un campo de simulación estética y política, como un proyecto problematizador. E1 ámbito proyectual del diseño intensivo es cuestionarse la presunción de las conexiones. Se trabaja desde la agitación de lo presuntamente objetivo. Desde la proyección de patrones de difracción, metáfora de un conocimiento situado, cuya práctica defiende la filósofa Donna Haraway: "Los patrones de difracción registran la historia de la interacción, la interferencia, el refuerzo, la diferencia. La difracción trata sobre la historia heterogénea y no sobre originales. A diferencia de las reflexiones, las difracciones no desplazan lo mismo en otra parte, de forma más o menos distorsionada”. (Haraway, 1997, p. 309).

La intensidad en los procesos de diseño hace visibles los procesos que determinan unas conexiones y no otras. Se orienta a establecer múltiples y dinámicas relaciones. Un lenguaje de diseño intensivo es una visión indirecta (figurada) de la realidad que crea entidades inestables, mutantes. Se trata de una práctica experimental basada en la desnaturalización de los dispositivos. Mediante tal práctica, el diseñador aborda con su trabajo aquello que Giorgio Agamben denomina la profanación de los dispositivos: la urgente restitución al uso común de lo que fue tomado y separado por ellos (Agamben, 2007, p. 264).

El prototipo Archisuits, que vemos en la Figura 6, nos remite a la urgente restitución al uso común de lo que fue tomado y separado por los dispo-

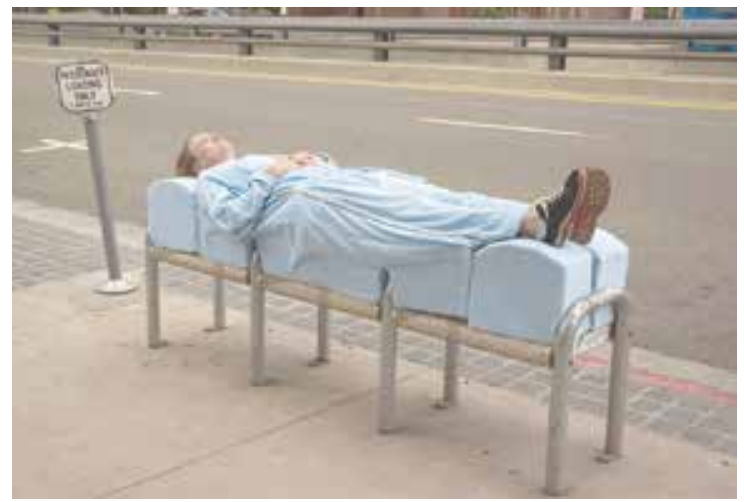

Fig. 6. Archisuits para dormir en un banco. Sarah Ross.

sitivos. Se trata de una prótesis que actualiza el banco con apoyabrazos. Sarah Ross ha diseñado un vestido que lleva adheridos unos cojines colocados tácticamente. Mediante la inserción de los cojines entre los apoyabrazos y por encima del nivel del respaldo, el banco ve restituido su uso como superficie donde descansar. El diseño modular aprovecha la forma estandarizada de los bancos de la ciudad para proyectar su contra forma. Tal oposición entre formas, materializa la oposición política y la pone en acción. Neutraliza la condición del banco como Anti-objeto. Observemos que el rediseño del banco ejerce una doble función: por un lado, descifra y visibiliza una política de las cosas y, por el otro, revoca su determinación.

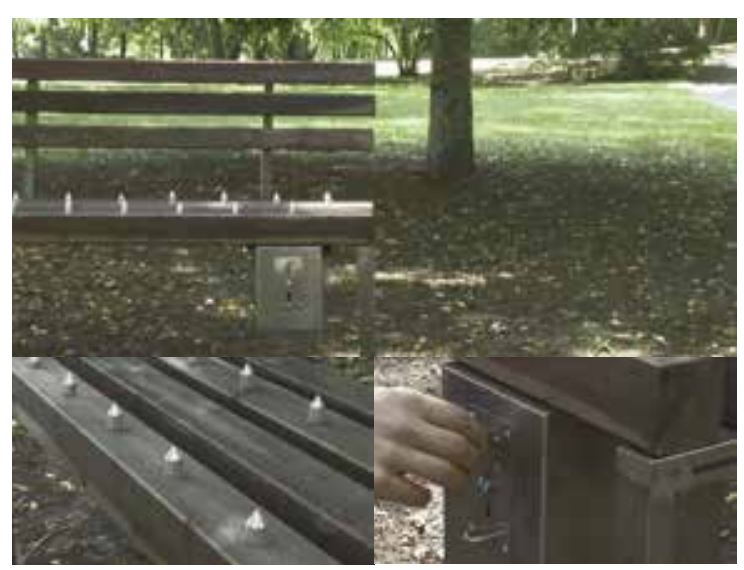

Fig. 7. Pay \& Sit Private Bench. Fabian Brunsing. 2008. 
El conjunto de imágenes de la Figura 7 ilustra el ejercicio de Fabian Brunsing, estudiante del programa de diseño de la interfaz de la FH Potsdam y la Parsons School of Design de Nueva York. Pay \& Sit Private Bench consiste en un banco cubierto con puntas de metal retráctiles y una ranura para monedas. Cuando se inserta la moneda en la ranura, los pinchos se retraen y se puede reposar durante un período fijo de tiempo antes de que se active la alarma. Unos segundos después del timbre, los pinchos vuelven a levantarse.

El experimento de Fabian Brunsing toma una afilada forma de impostura. Se apropia de los procesos de solidificación de los lenguajes de diseño con el fin de poner en evidencia el no-lugar que estos encierran. Exagera hasta tal punto su adhesión a la estética de la seguridad (Figura 8), que hace visible el kitsch que en ella reside. Asimismo, incorpora a su prototipo un intercambio monetario vinculado a un intervalo de tiempo. Con esta acción, el banco pierde la condición de último refugio del ocio productivo. Disuelve la noción de espacio público, como tantos otros objetos. Fabian Brunsing publica un vídeo presentando el prototipo en una web de aspecto corporativo. Es interesante cómo los medios de noticias en la red se hacen eco del producto sin advertir la impostura del diseño. Una vez transmitido el mensaje, la recepción acrítica en el contexto mediático se encarga de legitimarlo: los redactores se centran, en unos casos, en una crítica seria y comprometida y, en otros, en ponderar su implantación en las ciudades. La estética del banco se ha mimetizado con la imagen de consenso. El efecto es el de una broma que no ha sido entendida. El proyecto Pay \& Sit Private Bench aprovecha la potencia de los medios de comunicación para desnaturalizar el dogma encerrado en la estética de control. De esta forma, el artista consigue rasgar la cortina del consenso.

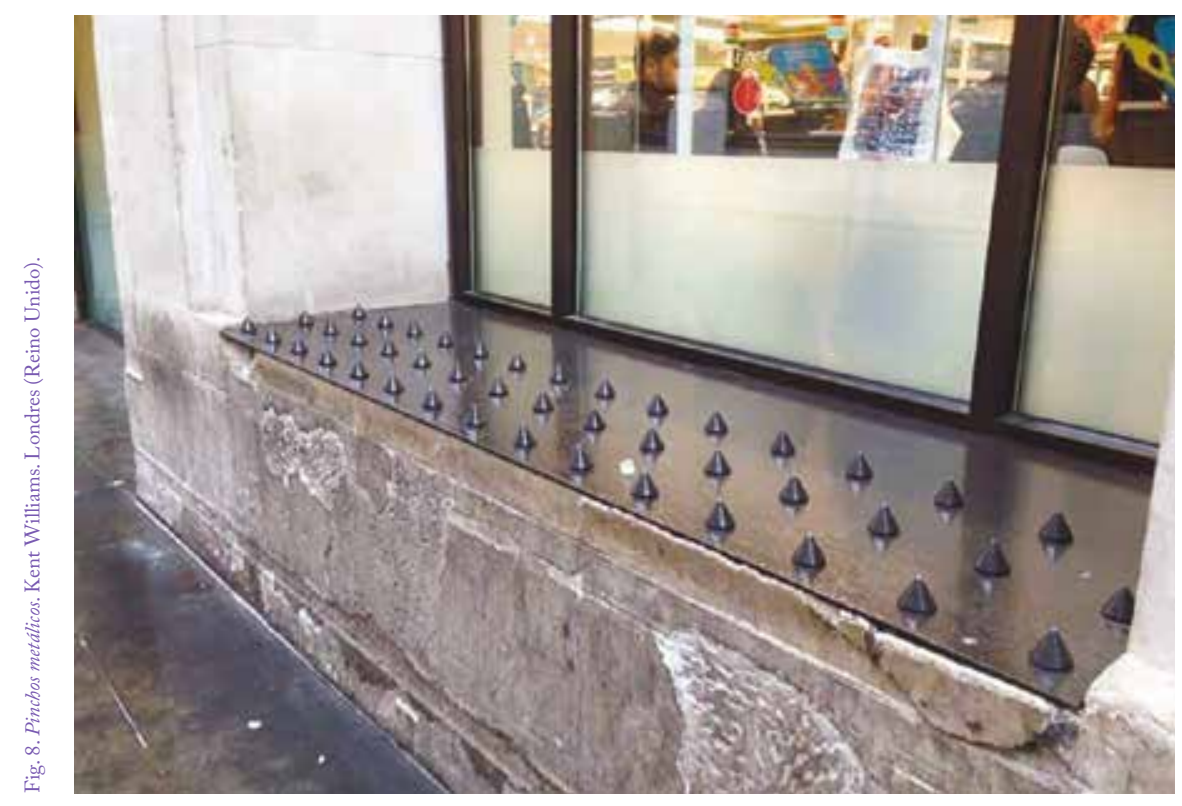




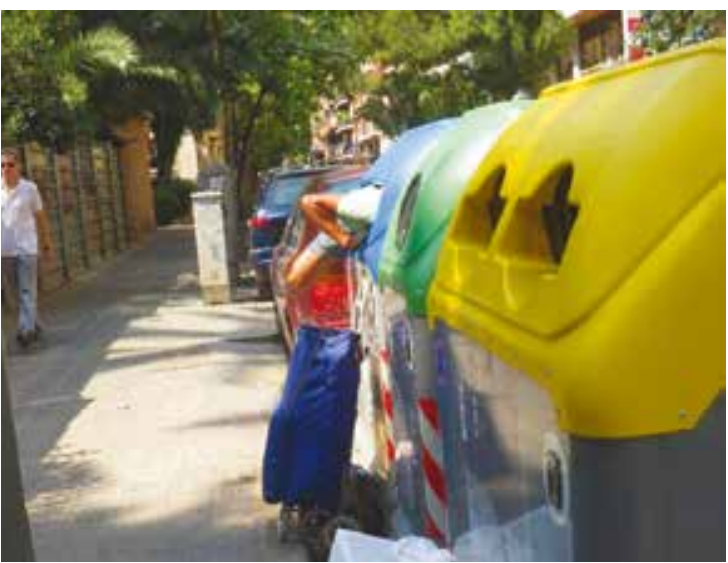

José Antonio Millán. El recogedor de metal como Jonás. Barcelona. 2014.

\section{Contenedores que vomitan diseñadores}

El diseñador ejerce su oficio amparado en la utilidad de sus proyectos dentro del marco legitimador del mercado institucional. Su trabajo se centra en lo objetivamente funcional y en la evocación al gusto. Se comporta como el testigo modesto: "el ventrílocuo legítimo y autorizado del mundo de los objetos, sin añadir nada de sus meras opiniones, de su corporeidad parcial. De esta manera recibe el extraordinario poder de establecer los hechos. Es testigo: es objetivo; garantiza la claridad y la pureza de los objetos" (Haraway, 1997, p. 223). Lo hace desde una posición aparentemente neutra, desde una tribuna que le infunde una rara asepsia política; aportando soluciones a un problema de orden social que viene diagnosticado desde esferas objetivas. Y lo hace modestamente. El sociólogo Bruno Latour (2008) percibe esta modestia en el diseño; un sector que según su punto de vista está dedicado, no a construir o hacer cosas, sino más bien a introducir una modificación sutil (un rediseño, una actualización).

Aún así, el diseñador comparte con el ingeniero el hecho de ser un mediador entre el objeto y sus usuarios. Ambos, tejedores del front-end y el back-end de nuestras interfaces cotidianas, dan uniformidad a las condiciones materiales de uso. El grupo de ingenieros críticos The Critical Engineering Working Group, en uno de los puntos de su manifiesto, da cuenta de la magnitud de afectaciones que tiene su trabajo: "el ingeniero crítico sabe que cualquier obra de ingeniería inicia un proceso de ingeniería con el propio usuario, directamente proporcional al nivel de dependencia del usuario respecto a la obra" (Oliver, Savičić y Vasiliev, 2011). Es decir, ante el diseño del contenedor cabría preguntarse ¿cuál es el nivel de dependencia del recogedor de metal? Leamos otro de los puntos del manifiesto y veamos como se posiciona ante la determinación política de los objetos que genera su trabajo: "El ingeniero crítico observa el espacio que hay entre la producción y el consumo de la tecnología. El ingeniero crítico actúa con rapidez ante los cambios que se producen en este espacio y pone de manifiesto los momentos de desequilibrio y decepción". El ingeniero crítico observa y actúa ante los desequilibrios que genera su trabajo. La consecución de los objetivos técnicos del contenedor se basan en la capacidad de infiltrar al objeto una mecánica de exclusión, por tanto, un buen diseño del contenedor habrá generado un desequilibrio entre su producción y los usuarios (explotación de la consciencia ecológica, objetivación del recogedor). Sin embargo, el diseñador del contenedor no es capaz de percibirse como el único eslabón entre la policía y el objeto.

El trabajo del diseñador, añadiendo, remediando, modificando cosas desde dentro (desde el código, desde la forma que permite expulsar recogedores), atañe tanto a su creatividad como a su autorregulación política. Su subjetividad se pliega a las objetivas funciones de control que, 
aunque no le pertenecen, guían su trabajo. Al integrar los vomitorios al formateo de sus objetos, el diseñador contribuye a absorber la productividad de la acción ecológica (seleccionar los desechos para su reciclaje) y perpetuar el cuerpo como desecho (expulsión del recogedor, incineración de desechos no reciclables). Su prototipo omite las disensiones, controversias y contradicciones que tendrá su convivencia en el ecosistema de los demás cuerpos en el espacio público.

Sin embargo, la práctica diseño puede superar sus complejos asépticos: ya no tiene la coartada de ceñirse a la objetividad técnica. En un contexto de estetización de los dispositivos de producción, el diseñador es la figura que implementa sus condiciones reguladoras. En su trabajo, trata en vano de obviar que ya no puede imaginar las cosas en sí mismas. Advierte que los aburridos soportes, mediante los que entendemos e imaginamos el mundo, ya llevan implícita una dimensión normativa. Frente a estas problemáticas, el diseñador se encuentra en una posición privilegiada para emprender la restitución al uso común de los objetos. La superación del corsé normativo, permitiría adquirir libertad de juego para explorar los espacios de intensidad en los procesos de diseño. La práctica del diseño se presta a desarrollar una ética interfacial, basada en la mejora de las condiciones de interacción y a facilitar relaciones simétricas con otros cuerpos en el espacio. Para hacerlo posible, el lenguaje proyectual se cuestiona: ¿Cómo se verán afectados los objetos de diseño, o cómo van a afectar a otros organismos de su entorno? El diseñador crítico toma las respuestas a esta pregunta como algo provisional. Entiende los objetos de diseño no como algo dado, sino como algo en proceso: evitar la tendencia a la mitificación requiere de códigos abiertos, de una mentalidad maker, de facilitar las conexiones tanto binarias como a escala humana. Requiere oponer al diseño inteligente y su catálogo de cajas negras, un diseño de los devenires que permita la apropiación pública de los productos que se ponen en circulación.

\section{Roc Albalat Gimeno}

Diseñador gráfico y realizador audiovisual en el estudio Taller Estampa. Profesor colaborador del Máster en Teoría y Práctica del Documental Creativo (Universidad Autónoma de Barcelona). Miembro de L'Automática, colectivo de impresión tipográfica. Grado en Diseño cursado en Bau, Centro Universitario de Diseño de Barcelona.

E-mail: roc@tallerestampa.com 


\section{Referencias}

Agamben, G., 2007. ¿Qué es un dispositivo? Sociológica, 73, pp. 249-264 [Online] Disponible en: <http://www.revistasociologica.com.mx/pdf/7310.pdf> [Fecha de consulta: 19 de agosto del 2016].

Agamben, G., 2014. Para una teoría de la potencia destituyente. [Online] Disponible en:

<https://artilleriainmanente.noblogs.org/post/tag/potencia-destituyente/> [Fecha de consulta: 26 de agosto del 2016].

Albalat, R., 2016. La ciutat com a interfície. En: T. Martínez, J.L. Marzo, eds. 2016. Interface politics. 1st Internacional Conference 2016.

Barcelona: Bau Centre Universitari de Disseny, pp. 225-240.

Biblica, 1999. Mateo 12:40 [Online] La Santa Biblia, Nueva Versión Internacional. Disponible en:

$<$ https://www.biblegateway.com/passage/?search=Mateo+12\%3A40\&version $=\mathrm{NVI}>$

[Fecha de consulta: 3 de noviembre del 2016].

Braidotti, R., 2013. Lo Posthumano. Barcelona: Gedisa.

Callon, M., 1991. Techno-economic networks and irreversibility. En: J. Law, ed. 1991. A Sociology of Monsters: Essays on Power, Technology and Domination. Sociological Review Monograph n. 38.

London: Routledge, pp. 132-164.

Clough, P., 2008. The Affective Turn: political economy, biomedia and bodies. Theory, Culture E' Society, 25(1). pp.11-22.

de Certeau, M., 2000. La invención de lo cotidiano.

México: Universidad Iberoamericana.

DeLanda, M., 2009. Ecology and realist ontology. En: B. Herzogenrath, ed. 2009. Deleuze/Guattari E' Ecology.

London: Palgrave Macmillan, pp. 23-41.

Deleuze, G., Guattari, F., 1993. A Thousand Plateaus.

Minneapolis: University of Minnesota Press. 
Ecoembes, 2014. Concurso para evitar o disminuir los hurtos de papel cartón en los contenedores. [Online] Disponible en:

<https://www.ecoembes.com/es/administraciones/recogida-selectiva/ concurso-disminuir-hurtos-de-papel-carton>

[Fecha de consulta: 24 de agosto del 2016].

Fuller, M., 2016. Underspecified Dreams of Parts and Wholes.

Inmaterial. Diseño, arte y sociedad, 1(1), pp. 79-86.

Haraway, D., 1997. Testigo-Modesto@.Segundo-Milenio. HombreHembra _Conoce_Oncoraton. Feminismo y tecnociencia. Barcelona: UOC.

Kafka, F., 1998. El castillo. Buenos Aires: Buró editor.

Latour, B., 1991. Technology is Society Made Durable. En: J. Law, ed. 1991. A Sociology of Monsters: Essays on Power, Technology and Domination. Sociological Review Monograph n.38. London: Routledge, pp. 103-132.

Latour, B., 2008. A Cautious Prometheus? A Few Steps Toward a Philosophy of Design (With Special Attention to Peter Sloterdijk).

En: F. Hackney, J. Glynne y V. Minto, eds. 2009. Proceedings of the 2008 Annual International Conference of the Design History Society,

Boca Raton: Universal-Publishers, pp. 2-10.

Lipovetsky, G., Serroy, J., 2015. La estetización del mundo. Vivir en la época del capitalismo artístico. Buenos Aires: Anagrama.

Marx, K., 2010. El Capital. Libro Primero. El proceso de producción del capital. Volumen 1. Madrid: Siglo XXI.

Millán, J., 2014. El recogedor de metal como Jonás. [Online] Disponible en: <http://jamillan.com/paralavista/contenedor.htm>

[Fecha de consulta: 3 de noviembre del 2016].

Oliver, J., Savičić, G., Vasiliev, D., 2011. The Critical Engineering Manifesto. [Online] Disponible en:

<https://criticalengineering.org/es>

[Fecha de consulta: 19 de agosto del 2016]. 
Porreta, D., 2010. Barcelona, ¿ciudad del miedo?: urbanismo "preventivo" y control del espacio público. DC. Revista de crítica arquitectónica, 19-20, pp. 183-192. [Online] Disponible en:

$<$ http://upcommons.upc.edu/handle/2099/10607>

[Fecha de consulta: 19 de agosto del 2016].

Rancière, J., 1998. Politica, identificación y subjetivación.

[Online] Disponible en:

<http://www.catedras.fsoc.uba.ar/heler/poliyidenranciere.htm>

[Fecha de consulta: 10 de agosto del 2016].

Savicic, G., Savic, S., 2013. Unpleasant design. Belgrade: G.L.O.R.I.A.

Survival Group, 2005. Anti-sites. [Online] Disponible en:

$<$ http://www.survivalgroup.org/anti-site.html>

[Fecha de consulta: 25 de agosto del 2016].

Tiqqun, n.d. Una metafísica crítica podría nacer como ciencia de los dispositivos. [Online] Disponible en:

<http://tiqqunim.blogspot.com.es/2015/05/una-metafisica-critica-podria-nacer.html>

[Fecha de consulta: 24 de agosto del 2016].

Tort, J., 2013. La multinacional Ros Roca entra en els mercats asiàtics i del sud d'Àfrica. El Punt Avui. [Online] 26 de enero. Disponible en: 〈http://www.clipmedia.net/ficheros/2013/01_ene/st181.pdf> [Fecha de consulta: 24 de agosto del 2016].

Winner, L., 1986. The whale and the reactor. A Search for Limits in an Age of High Technology. Chicago: The University Of Chicago Press. 